\title{
Lack of objective evidence of stiffness in rheumatoid $\frac{\frac{0}{n}}{m}$ arthritis
}

\author{
P S HELLIWELL, A HOWE, AND V WRIGHT
}

From the Rheumatism Research Unit, University Department of Medicine, The General Infirmary at Leeds and the Regional Rheumatology Centre, Royal Bath Hospital, Cornwall Road, Harrogate, Leeds

SUMMARY Metacarpophalangeal joint stiffness was measured using a new microprocesso $\frac{\varpi^{2}}{2}$ controlled arthrograph in 135 patients with rheumatoid arthritis. Subjects were prospectivel祚 subdivided according to the stage of the disease in the joint. Compared with a normal populationo stiffness variables in active rheumatoid arthritis were decreased, significantly so for non-elastiङ stiffness. This study casts doubts on the literal interpretation of symptomatic stiffness as ant indicator of disease activity in rheumatoid arthritis and suggests a number of explanations for the discordant result.

Key words: joint stiffness, microprocessor.

Symptomatic stiffness heads the list of diagnostic criteria in rheumatoid arthritis (RA). ${ }^{1}$ A number of attempts to quantify this symptom have been made over the last 25 years following the original work of Wright and Johns ${ }^{2}$ and have, on the whole, tended to confirm the patients' impression that physical stiffness is increased in RA. We have challenged this belief, indicating possible sources of error in previous methodologies. ${ }^{3}$

A further source of confusion may arise if patients with RA are treated as an homogeneous group. The physical characteristics of an architecturally normal joint affected by an inflammatory synovitis are likely to be different from those of a joint whose structure has been completely disorganised by the rheumatoid process. We have prospectively subdivided patients with RA affecting the hands into four distinct subgroups, according to the stage to which their disease has progressed, and have compared stiffness values in these subgroups with those of the normal population.

\section{Patients and methods}

Stiffness was measured in the third metacarpophalangeal (MCP) joint of the dominant hand with the Leeds microprocessor controlled arthrograph. ${ }^{4}$

Accepted for publication 18 February 1988.

Correspondence to Dr P Helliwell, Rheumatology and Rehabilitation Research Unit, School of Medicine, 36 Clarendon Road, Leeds LS2 9PJ.
Stiffness was measured in abduction/adduction 앵ํㅇ was defined as the passive resistance to motion at the joint. The standard test consisted of a sinusoied displacement of $4^{\circ}$ amplitude at a frequency of 0 . $\mathrm{Hz}$. Measurements were made of stiffness aroun $\Phi$ the equilibrium position of the joint; this wao defined as the point at which there are no net force\& acting on the joint, and is the position the finge $\vec{\Phi}$ would adopt in full relaxation. The hysteresis loop thus obtained were described by the following variables: mean slope (calculated by the leas. squares method) and hysteresis (which attempts to normalise the area of the loop by expressing it as o ratio with the area of a triangle fitted to the slope of the loop). Reproducibility of hysteresis loops acceptable in both normals ${ }^{4}$ and patients with RA.

All patients with RA fulfilled the diagnostio criteria for classical or definite disease. ${ }^{1}$ All patients were subdivided prospectively on the basis observable characteristics in the joint under study? as follows: 1. Active RA: pain and soft tissug swelling present in the joint in the absence of clinica subluxation and gross bony hypertrophy; 2 . Inactive RA: no soft tissue swelling but bony swelling in the् absence of clinical subluxation; 3. Clinical and radiographic subluxation of the joint regardless of other features; 4. Joints treated by arthroplasty.

Most of the subjects were inpatients at the Royal Bath Hospital, Harrogate. All measurements werg taken between 11 am and $4 \mathrm{pm}$, at the time of th minimal symptomatic stiffness, though most patientक 
still complained of this symptom. Concurrent treatment was not altered during the measurements.

The following information was collected from each patient: age, sex, duration of disease, treatment with non-steroidal anti-inflammatory drugs (NSAIDs), erythrocyte sedimentation rate, and Ritchie articular index. An $x$ ray assessment was carried out using the system of Larsen et al $^{6}$ : the maximum score for the individual MCP joint was 5 , but in addition a score was obtained for both hands for which the maximum was 140 (this is obtained by multiplying the score for each wrist by 5 , and including all the MCP joints and the proximal interphalangeal joints except those of thumbs). Finger circumference was measured just distal to the web space of the finger with a plastic, spring loaded arthrocircometer.

Normal values were previously obtained from measurements of 128 subjects, aged 10-83 years, equally divided between the sexes. ${ }^{4}$ Stiffness variables were found to be largely dependent on finger circumference, and so normal values were presented as regression lines with their respective parallel centile lines.
STATISTICAL ANALYSIS

Because of the close relation between finger circumference and stiffness variables it was not possible simply to compare raw values obtained in the patient groups with those from the normal population. Regression lines derived from patient groups were compared with normal regression lines using covariance analysis. Mean values were adjusted by a similar technique and compared by $t$ test using the pooled standard error. ${ }^{7}$

\section{Results}

Table 1 summarises the clinical details of the patient groups. In all, 135 patients were examined and measured. Despite the fact that subdivision of patients was made on local changes, the duration of disease reflects this arbitrary classification. Similarly, the total $x$ ray score for both hands increased progressively with disease group. As would be expected patients classified as active RA had the largest fingers.

Table 2 presents the results of the statistical comparison of the patient groups with the normal

Table 1 Summary of clinical details

\begin{tabular}{|c|c|c|c|c|}
\hline & $\begin{array}{l}\text { Active } \\
R A\end{array}$ & $\begin{array}{l}\text { Inactive } \\
R A\end{array}$ & $\begin{array}{l}\text { Subluxated } \\
M C P\end{array}$ & Arthroplasty \\
\hline n & 66 & 32 & 32 & 5 \\
\hline Age (years)* & $56 \cdot 7$ & 65 & $59 \cdot 4$ & $59 \cdot 8$ \\
\hline Female & 53 & 19 & 24 & 4 \\
\hline Male & 13 & 13 & 8 & 1 \\
\hline Duration of disease (years)* & $8 \cdot 3$ & $15 \cdot 3$ & $17 \cdot 2$ & $18 \cdot 6$ \\
\hline Treatment with NSAIDs & 43 & 21 & 29 & 4 \\
\hline $\operatorname{ESR}(\mathrm{mm} / 1 \mathrm{st} \mathrm{h})$ & 40 & 33 & 34 & 48 \\
\hline Ritchie index ${ }^{*}$ & 19 & 17 & 17 & 20 \\
\hline \multicolumn{5}{|l|}{$x$ Ray score* } \\
\hline Individual MCP joint & 1.9 & $1 \cdot 6$ & 5 & - \\
\hline Hands & 47 & 54 & 94 & 97 \\
\hline Finger circumference $(\mathrm{mm})^{*}$ & $58 \cdot 3$ & $56 \cdot 3$ & $56 \cdot 5$ & $56 \cdot 8$ \\
\hline
\end{tabular}

*Indicates mean value

$\mathrm{MCP}=$ metacarpophalangeal; NSAIDs=non-steroidal anti-inflammatory drugs; ESR=erythrocyte sedimentation rate

Table 2 Comparison of patient groups with normals

\begin{tabular}{|c|c|c|c|c|c|c|c|c|}
\hline & \multicolumn{4}{|c|}{ Mean slope $v$ finger circumference } & \multicolumn{4}{|c|}{ Hysteresis $v$ finger circumference } \\
\hline & \multirow[t]{2}{*}{$F$ (slope) } & \multicolumn{3}{|c|}{ Adjusted variables $\left(\mathrm{Nm} / \mathrm{deg} \times 10^{4}\right)$} & \multirow[t]{2}{*}{$F$ (slope) } & \multicolumn{3}{|c|}{ Adjusted variables (\%) } \\
\hline & & Disease & Normal & $t$ & & Disease & Normal & $t$ \\
\hline Active RA & $2 \cdot 14$ & $75 \cdot 1$ & $79 \cdot 1$ & 0.6 & $1 \cdot 32$ & $31 \cdot 5$ & $36 \cdot 2$ & $2 \cdot 64^{* *}$ \\
\hline Inactive RA & 0.02 & $108 \cdot 8$ & $76 \cdot 8$ & $3 \cdot 5^{*}$ & $1 \cdot 5$ & $31 \cdot 5$ & $36 \cdot 6$ & $2 \cdot 17^{* * *}$ \\
\hline Subluxed MCP & $2 \cdot 16$ & 63.0 & $77 \cdot 5$ & $1 \cdot 60$ & $1 \cdot 4$ & $33 \cdot 1$ & $36 \cdot 3$ & 1.44 \\
\hline
\end{tabular}

${ }^{*} \mathrm{p}<0.001 ;{ }^{* *} \mathrm{p}<0.01 ;{ }^{* * *} \mathrm{p}<0.05$. 
population. The arthroplasty group was omitted from this analysis because of insufficient numbers. The results are also presented graphically in Fig. 1, where the mean values for each patient group have been superimposed on the normal regression lines.

Although the relation between mean slope, hysteresis, and finger circumference was not as close as for the normal group, none of the differences was statistically significant. The data in Fig. 1, however, demonstrate marked differences in stiffness between the patient groups. Elastic stiffness (mean slope) was decreased in the active RA, subluxed MCP, and arthroplasty groups, but increased in the inactive RA group. Only the inactive RA group was significantly different from normal.

The results for hysteresis were not as straightforward. Dissipative or viscous stiffness is derived from the area of the hysteresis loop, and we expressed this variable as a ratio with the area of a triangle fitted to the slope of the loop. Thus if both area and slope decreased hysteresis did not change.
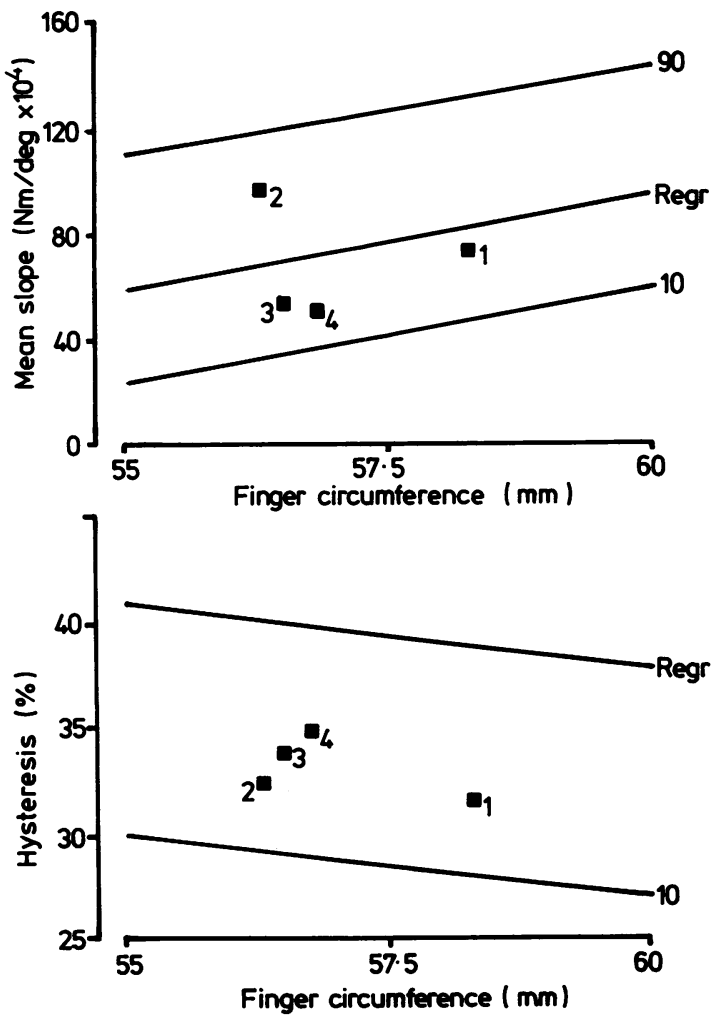

Fig. 1 Mean stiffness values for patient groups superimposed on normal regression lines. $1=$ Active $R A$; $2=$ Inactive $R A ; 3=$ Subluxed $M C P ; 4=$ Arthroplasty; $10=10$ th centile $; 90=90$ th centile.
If the area fell disproportionately in relation to the slope then the hysteresis would also fall. For all foupen? groups hysteresis was lower than normal, but only ire the inactive RA group was the area greater tharf? normal. For hysteresis both the active and inactive RA groups were statistically significantly differen from normal.

\section{Discussion}

In a group of patients with RA only those patientsconsidered to have inactive disease were found to bew stiffer than normal. All patients had either past of present inflammatory involvement of the join $\overline{\underline{5}}$ under study and although not all of them com plained of stiffness, in most this was a majoto complaint. How then can we explain this discrepor ancy and the discordance between the results of this study and earlier studies appearing to confirm this subjective impression?

We have previously shown that the results $o p^{p}$ earlier studies may be misleading because stiffnes measurements were not made in relation to the equilibrium position of the joint. ${ }^{3}$ This is particu零 larly true of previous arthrographs measuring the hand $^{28}$ and knee. ${ }^{9}$ Indirect measures of stiffnessso may for the same reason prove misleading. More recently, where stiffness measurements ha\% been made using the equilibrium position as as datum, patients with RA have been found to haved similar or decreased stiffness values compared with normal. ${ }^{12} 13$

Although abduction/adduction as pure move $\vec{\partial}$ ments are rarely used in normal digital activity, hand $B$ function often requires composite movements of the fingers. Flexion and extension are the principap. movements, but abduction and adduction still playe an integral part in such manoeuvres as twisting turning, and writing. Furthermore, the shape of the joint is basically biconvex over the mid-range of movement, and so similar information should be obtained in abduction/adduction as in flexion extension. Only when much larger amplitudes of displacement are used may additional or differents information be obtained. Measurements of stiffness. in flexion/extension support this view, provided thaf the measurements are made around the mid-range of movement of the joint and that the equilibrium position is used as a reference datum. ${ }^{12} 13$

It may be argued that because patients continued with their normal treatment during these measure? ments, stiffness was absent owing to therapeutie intervention. Despite efforts to take measurements at a time of day when stiffness is symptomatically at a minimum, and despite continuing treatment witl NSAIDs, however, most patients complained of 
some degree of stiffness at the time of the measurements. Moreover, NSAID usage was similar in all four subgroups, including the stiffer patients with inactive RA. Furthermore, a group of 14 patients with RA, in whom all NSAID treatment was discontinued for the purpose of studying circadian variation, did not have stiffness values dissimilar from those of the present group: mean stiffness values (SEM) at $3 \mathrm{pm}$ : mean slope 62.5 (9.3) $\mathrm{Nm} / \mathrm{deg} \times 10^{4}$; hysteresis $33(3 \cdot 1) \%$.

One possible explanation is that patients feel stiffer because their fingers swell, thus moving them along, but not above, the regression line for that particular finger circumference. This is an attractive theory, but in practice one would therefore expect the mean finger circumference of patients with, for example, active RA to exceed the mean finger circumference of the normal group. Values obtained were $58.3 \mathrm{~mm}$ and $59.5 \mathrm{~mm}$ for RA and normals respectively, and, thus, although not entirely invalidating this suggestion, these results make the hypothesis less likely. Another way of testing the validity of this hypothesis is to look at a group of patients with active RA at times when their subjective stiffness is changing rapidly; if changes in objective stiffness parallel changes in subjective stiffness then further support for this theory would be obtained. The results of such interventions will form the subject of a further paper: preliminary results indicate a poor correlation between subjective and objective measures.

As a major feature of RA is swelling of the small joints of the hand it is surprising to find that this group of patients has a mean finger circumference less than that of a control group. Possibly this is a result of measuring the nearest possible site to the MCP joint rather than the joint itself. A more likely explanation is that patients with RA have associated disuse atrophy of non-articular tissues, the net affect of which is little change in the finger circumference as measured.

Possibly weakness contributes to the symptom of stiffness, although, as has been pointed out previously, patients with myopathy do not usually complain of stiff joints. ${ }^{14}$ The reason for this is that, even in the weakest rheumatoid subjects, maximal muscle force easily exceeds the force necessary to move the joint. ${ }^{15}$ Furthermore, the contribution of passive stretching of muscles to stiffness in the finger is approximately $50 \%,{ }^{16}$ and so the profound muscle wasting consequent on inflammatory synovitis is likely to decrease stiffness at the joint. This is reflected in the low hysteresis values obtained in active and destructive RA.

It may be that limitation of movement rather than increased resistance to movement is the main complaint, and there is some evidence for this from the study of Rhind et al. ${ }^{17}$ Preliminary studies using a fixed torque goniometer have tended to confirm this impression, but the pain experienced when rheumatoid joints are moved to the extremes of their range of movement complicates this measurement because involuntary resistance to movement may occur due to pain.

Perhaps a semiological confusion exists in RA. This problem can be demonstrated by asking patients exactly what they mean by 'stiffness' ${ }^{17}$ Patients may not only confuse pain and stiffness, but in fact they may be using 'stiffness' as a convenient descriptive term for other sensations arising in the joints. Alternatively, it may be that painful stimuli from the joints modify, at a spinal level, the sensitivity of mechanoreceptors in joint, ligament, and capsule. ${ }^{18}$ A recent study demonstrating the efficacy of a pure analgesic to relieve morning stiffness in RA would support this theory. ${ }^{19}$

The findings of this study are readily explained on a pathological basis. In active RA inflammatory synovitis causes distension and distortion of the joint capsule and collateral ligaments and ultimately leads to attenuation of these structures. At the same time there is profound muscular weakness and together these changes would be expected to produce a fall in the resistive torque with a disproportionately larger fall in the dissipative torque at the joint. If the disease progresses to such an extent that disorganisation and subluxation of the joint occurs then the periarticular structures are likely to exert little resistance to passive movement. At this point there is a profound loss of function in the finger with further muscular atrophy: this is reflected in the further decrease in stiffness recorded from subjects with subluxed joints. If, however, the inflammation subsides before this point then healing by fibrosis may well result in an increased resistive torque locally, and the improved function consequent on loss of inflammatory pain is likely to result in reclamation of at least some of the muscle bulk.

This study suggests that our interpretation of symptomatic stiffness in RA is incorrect. The result does not, however, invalidate the use of the term 'stiffness' for diagnostic purposes or as a clinical indicator of disease activity. Further investigation is required to determine exactly what the patient experiences as 'stiffness' so that a relevant, quantifiable measure of the symptom can be obtained.

We are grateful to the Arthritis and Rheumatism Council for financial assistance. We also thank Mrs Hilary Sharp for typing the manuscript.

\section{References}

1 Ropes M W. Bennett G A. Cobb S. Jacox R. Jessar R A. 1958 
Revision of diagnostic criteriafor rheumatoid arthritis. Arthritis Rheum 1959; 2: 16-20.

2 Wright V. Johns R J. Physical factors concerned with the stiffness of normal and diseased joints. Bulletin of the Johns Hopkins Hospital 1960; 160: 215-31.

3 Helliwell PS, Howe A. Wright V. The measurement of stiffness in the rheumatoid hand. Eng Med 1987: 16: 203-7.

4 Howe A. Thompson D. Wright V. Reference values for metacarpophalangeal joint stiffness in normals. Ann Rheum Dis 1985; 44: 469-76.

5 Helliwell P S. The measurement of stiffness and strength in the rheumatic hand. University of Oxford, 1987. (DM thesis.)

6 Larsen A. Dale K. Eck M. Radiographic evaluation of rheumatoid arthritis and relevant conditions by standardised reference films. Acta Radiol /Diagn/ (Stockh) 1977; 18: $481-91$.

7 Snedecor G W. Cochran W G. Statistical methods. 7th ed. Iowa: Iowa State University Press. 1980.

8 Bäcklund L, Tiselius P. Objective measurement of joint stiffness in rheumatoid arthritis. Acta Rheumatologica Scandinavica 1967; 13: 275-88.

9 Goddard R, Dowson D, Longfield M D. Wright V. The measurement of stiffness in human joints. Acta Rheologica 1969: 2: 229-34.
10) Hicklin J A. Wighton R J. Robinson F J. Measurement finger stiffness. Ann Phys Med 1968: 9: 234-42.

11 Ingpen M L. Kendall P. A simple apparatus for assessment of stiffness. Ann Phys Med 1968: 9: 203-5.

12 Thompson D T. A study of knee joint stiffness. University Leeds. 1978. (PhD thesis).

13 Yung P. The human metacarpophalangeal joint: quantification of stiffness and the effects of treatment. University of Durham 1981. (MSc thesis).

14 Wright V. Plunkett T G. Scientific assessment of the results of physical treatment-measurement of stiffness. Ann Phys Mece्? 1966: 8: 28(1-91.

15 Helliwell P. Howe A. Wright V. Functional assessment of the $\overrightarrow{0}$ hand: reproducibility, acceptability, and utility of a new system for measuring strength. Ann Rheum Dis 1987: 46: 2113-8.

16 Johns R J. Wright V. Relative importance of various tissues in joint stiffness. J Appl Physiol 1962; 17: 824-8.

17 Rhind V M. Unsworth A. Haslock I. Assessment of stiffness in rheumatology: the use of rating scales. BrJ Rheumatol 1987: 26: 126-30.

18 Harvey A R. Neurophysiology of rhcumatic pain. Clini Rheumatol 1987; 1: 1-26.

19 Emery P. Gibson T. A double-blind study of the simpleo analgesic nefopam in rhcumatoid arthritis. $\mathrm{Br} J$ RheumatoP 1986: 25: 72-6. 